Mem. Inst. Oswaldo Cruz, Rio de Janeiro, Vol. 77(4) :367-384, out./dez. 1982

\title{
ENSAYOS METODOLOGICOS PARA LA INVESTIGACION DE RESERVORIOS DE LEISHMANIA SPP EN LOS ANDES VENEZOLANOS
}

\author{
ANA LUGO YARBUH \\ J.V. SCORZA
}

Se describen dos técnicas, presuntiva y confirmativa, para la investigación de mamiferos que pudieran ser reservorios de Leishmania que parasitan al hombre.

Se investigan los cambios en los títulos de inmovilización y aglutinación de promastigotos de cultivo por los sueros de animales normales y expuestos una o varias veces a la inoculación in tradérmica de pequeñas dosis de promastigotos vivos. Se registra una caida de los titulos de aglutinación en los sueros de hamsteres, de Holochilus venezuelae $y$ de Didelphis marsupialis después de la inoculación con L. mexicana mexicana de Panamá y de $\mathrm{L}$. garnhami de la región de los Andes venezolanos. Se discute la naturaleza de estos fenómenos.

Se han hecho xenodiagnósticos con Lutzomyia townsendi en Holochilus venezuelae $y$ Sigmodon hispidus infectados experimentalmente com $\mathrm{L}$. mexicana mexicana, $\mathrm{L}$. mexicana amazonensis, L. braziliensis y L. garnhami. Las pruebas fueron leidas mediante el examen microscópico de las gotitas de heces excretadas entre las 108 y 132 horas después de la ingesta infectante, tras colorearlas con Giemsa. Se obtuvieron resultados positivos en $23 \%$ de los experimentos usando mamiferos con lesiones localizadas, dejando a los flebótomos ingurgitarse libremente sobre animales anestesiados que poseian una hasta varias lesiones localizadas.

Hace veinte años el Profesor Pifano (1960) planteó la tesis del origen selvático de la leishmaniasis cutánea en el Neotrópico, señalando entonces que la información a mano "constituye la base para sospechar la existencia de nidos de zoonosis, en donde el agente causal debe haber circulado ininterrumpidamente a través de affos de un vertebrado selvático a otro, existiendo una íntima relación entre los Phlebotomus vectores y sus fuentes de alimentación". Para entonces los investigadores del Gorgas Memorial Laboratory, en Panamá, habían aislado Leishmania sp. de Proechimys semispinosus por hemocultivo (Anonimo, 1958).

El hallazgo de parásitos en animales domésticos fue un hecho tempranamente conocido; Pedroso (1913) demostró la presencia de Leishmania braziliensis en lesiones cu-

Facultad de Ciencias - Universidad de Los Andes - Mérida, Venezuela.

Este trabajo fue realizado con fínanciamiento del Consejo de Desarrollo Cientifico y Humanístico de la Universidad de los Andes, Venezuela y por el componente Leishmaniasis del Programa para el Desarrollo de las Naciones Unidas/Banco Mundial/OMS, Programa Especial para Investigaciones y Entrenamiento en Enfermedades Tropicales.

Recibido para publicación en 8 de Deciembre de 1981 y acepto en 8 de Febrero de 1982. 
táneas de los perros en el sureste del Brasil y posteriormente, Pifano (1940) demostró la presencia de amastigotos de L. braziliensis en un $8 \%$ de 97 perros examinados en el Estado Yaracuy, Venezuela.

La investigación de reservorios silvestres para los agentes etiológicos de las leishmaniasis tegumentarias en América, ha sido parte de los programas sobre epidemiología de estas dolencias en los últimos veinte años; un resumen sobre el papel de los pequeños mamíferos silvestres como reservorios, ha sido compendiado por Lainson \& Shaw (1978). Allí se revela que, por lo menos, veinticinco géneros de mamíferos, principalmente roedores, desdentados, marsupiales, primates y carnívoros, son hospedadores de L. braziliensis y de $L$. mexicana. El esfuerzo realizado se puede medir por el número de especímenes examinados en Panamá. Herrer, Christensen \& Baumer (1973) utilizando la técnica de cultivo de trocitos de piel, revisaron entre 1965 y 1972, cerca de 3000 mamíferos pequefos aparentemente sanos, hallando un 6,25\% de infecciones. En Brasil, Forattini (1960) había examinado por hemocultivo cerca de mil ejemplares también aparentemente sanos, con un $3 \%$ de positividad. El examen de animales con lesiones aparentes dá muy escasos resultados; $0,88 \%$ entre 681 mamíferos fueron hallados positivos tras el examen microscópico de frotes por Lainson \& Shaw (1978) en la región amazónica de Brasil. Las lesiones cutáneas son escasas en animales infectados; en un $89 \%$ de los casos positivos, la piel de los animales no exhibe alteraciones groseras (Herrer \& Christensen, 1975).

La endemicidad de la leishmaniasis, como enfermedad que afecta a las poblaciones rurales, es por una parte, un proceso dinámico que pasa por focos de endemia reciente, de alta endemia y de antigua endemicidad con casos esporádicos (Pifano, 1960). Por otra parte, su epidemiología encuadra dentro de las relaciones ecológicas entre poblaciones de parásitos, de hospedadores y de vectores (Bradley, 1972), donde el fenómeno del parasitismo depende del tipo de transmisión, de la regulación de las poblaciones de hospedadores y de la resistencia de hospedadores individuales. Las relaciones entre las poblaciones de hospedadores y de parásitos podrían reducirse a modelos donde lo fundamental es precisar, con exactitud, los parámetros que limitan o deciden de tales asociaciones poblacionales.

Tales puntos de vista demandan prácticas y económicas metodologías para cuantificar la frecuencia e intensidad del parasitismo en términos de potencialidad para infectar transmisores, para cuantificar su frecuencia en muestras poblacionales de reservorios naturales durante períodos prolongados en áreas endémicas, y también metodologías prácticas y económicas para precisar la frecuencia del parasitismo en los flebótomos vectores. Esta necesidad es tanto mas apremiante cuando se contempla la variedad de técnicas utilizadas para averiguar cuándo un mamífero se halla infectado y cuál es su importancia como reservorio para los transmisores. Las manipulaciones de laboratorio pasan por hemocultivos (Anonimo, 1958), cultivo de trocitos de piel en medios apropiados para tripanosómidos (Herrer, Thatcher \& Johnson, 1966), inoculación de sangre en hamsteres (Torrealba, Gomes-Nuñez \& Üloa, 1972), inoculación de visceras en hamsteres o cultivos de vísceras (Herrer \& Telford, 1969) y, desde luego, el examen microscópico minucioso de frotes de lesiones sospechosas de ser producidas por leishmanias. El uso simultáneo de todas estas técnicas, en estudios epidemiológicos prolongados, demandaría de un gran personal con extensos recursos materiales. La disección individual de flebótomos para la búsqueda de promastigotos infectantes para el hamster o la inoculación subcutánea de triturados de varios flebótomos en hamsteres, tan utilizada por los pioneros brasileños y mexicanos en investigaciones epidemiológicas, dá resultados tardíos y poco confiables.

En este trabajo describimos dos pruebas para el diagnóstico presuntivo de una infección por Leishmania spp. en un modelo experimental que incluye dos Cricetinae silvestres y un Didelphidae, inoculados experimentalmente con tres especies de Leishmania, usando como control a hamsteres de laboratorio, que son animales siempre susceptibles a la infección con cualquier especie de Leishmania. 
La primera prueba explora las modificaciones de los títulos de antícuerpos inmovilizantes y aglutinantes de promastigotos vivos de Leishmania spp., en animales normales nacidos en el laboratorio o en animales silvestres aparentemente sanos y provenientes de zonas no endémicas, que han recibido una o varias inyecciones intradérmicas de promastigotos vivos de Leishmania spp.; la segunda el empleo del xenodiagnóstico con hembras silvestres de Lutzomyia townsendi provenientes también de una localidad no endémica y un diseño original para la lectura de los xenodiagnósticos, sin necesidad de disecar a los insectos, cuando estos se han ingurgitado sobre dos Cricetinae silvestres experimentalmente infectados con una cepa de Leishmania garnhami.

El uso de las técnicas de inmovilización, de aglutinación o de inhibición de crecimiento de promastigotos de cultivo, fue introducido tempranamente como criterio para identificar taxonómicamente a los parásitos mediante el empleo de sueros de animales normales o inmunizados (Klingler, 1925); en otros casos para precisar la susceptibilidad o resistencia de animales sujetos a la infección con Leishmania spp. (Taub, 1956), para predecir la susceptibilidad de animales de laboratorio a la infección con los mismos parásitos (Ulrich, Ortiz \& Convit, 1968), o como técnica de simple diagnóstico serológico diferencial con parásitos modificados, como los ensayos de Allain \& Kagan (1975). En estos y otros trabajos se citan numerosas contribuciones sobre tales problemas.

Nuestra finalidad es diferente; se trata de investigar la acción vis a vis de sueros frescos de animales silvestres contra promastigotos de Leishmania spp. de una zona endémica, como una técnica presuntiva para orientar la investigación hacia la identificación de posibles reservorios.

El xenodiagnóstico con flebótomos fue propuesto por Christensen \& Herrer (1972) para detectar infecciones crípticas y asintomáticas producidas por $L$. braziliensis en el perezoso Choloepus hoffmanni, utilizando Lutzomyia gomezi cultivadas en el laboratorio. Posteriormente los mismos autores (Christensen \& Herrer, 1977) repitieron sus experiencias sobre 73 edentados de la misma especie, utilizando 1.165 ejemplares de $L u$. gomezi, detectando la infección por $L$. braziliensis en $49 \%$ de los mamíferos, con lotes de flebótomos que mostraron desde 4 hasta un $100 \%$ de infecciones.

\section{MATERIALES Y METODOS}

\section{I - Ensayos serológicos}

\section{- Animales experimentales}

Utilizamos quince hamsteres machos de la colonia de la Facultad de Medicina de la U.L.A. (Mérida, Venezuela), quince adultos de Holochilus venezuelae capturados en una zona no endémica para leishmaniasis en el llano centro-occidental de Venezuela y también doce adultos de Didelphis marsupialis capturados en la alta cordillera de los Andes de Mérida, a $1750 \mathrm{~m} . s . n$ m. donde no existen flebótomos mastozoófilos. Los roedores fueron mantenidos con ratarina concentrada para ratas, agua y calabazas frescas; los marsupiales con agua, cambures, huevos y ocasionalmente ratones jóvenes.

\section{- Aislados de Leishmania spp. y su cultivo}

Se utilizaron tres aislados de Leishmania. La cepa L. mexicana mexicana aislada por Herrer, Telford \& Christensen (1971) de Oryzomys capito de Panamá (cepa EV41, No. 1746), mantenida por inoculación en hamsteres. Las cepas HM y JAP aisladas de casos clínicos procedentes del Estado Mérida. El aislado HM con desarrollo peripilórico en Lu. townsendi (Ortiz, 1959) y JAP con desarrollo suprapilórico en la misma especie de flebótomo. Todas fueron mantenidas por inoculación subcutánea de amastigotos en la cara dorsal de los tarsos posteriores de hamsteres.

Hamsteres con lesiones tarsales producidas por L. mexicana y las cepas HM y JAP com 9-11 mm. de diámetro fueron sacrificados por sobreanestesia con éter, seccionán- 
doles los tarsos infectados después de bañarlos con alcohol de 70\%. En condiciones asépticas, se separó la piel y se tomaron fragmentos del tejido granulomatoso de la dermis, para triturarlos en un mortero de porcelana con solución salina estéril y penicilina $(1000 \mu \mathrm{s})$ y estreptomicina $(1 \mathrm{mg})$ por $\mathrm{ml} . ; 0,1 \mathrm{ml}$ del triturado fue sembrado en medio de cultivo NNN con sangre de conejo e incubado a $25^{\circ} \mathrm{C}$ durante siete días. De este primocultivo se hicieron pasajes seriados en el mismo medio de cultivo cada ocho días. Formas promastigotas de cultivo fueron utilizadas para inocular los animales experimentales y para preparar las suspensiones de parásitos vivos que se utilizaron en los ensayos serológicos para las determinaciones de los títulos de inmovilización y de aglutinación.

- Inoculación y sangrado de los animales para los ensayos serológicos

Volúmenes de $0,05 \mathrm{ml}$ de medio de cultivo de siete días de incubación, fueron inoculados intradérmicamente en la cara dorsal de las patas posteriores de hamsteres y de Holochilus venezuelae, y en la cara dorsal de la base de la cola, sin pelos, de $D$. marsupialis.

En el caso de los hamsteres se hizo una única inoculación; en el de los $H$. venezuelae y $D$. marsupialis se hicieron cuatro inoculaciones repetidas en el mismo sitio de la piel cada diez días. Cada especie de mamífero, en grupos de cuatro o cinco, fue inoculada con cada una de las tres cepas de parásitos: L. mexicana, HM y JAP.

Inmediatamente antes de la primera inoculación y en la víspera de cada una de las inoculaciones subsiguientes, se extrajo a los animales 1-2 ml. de sangre por cardiopuntura para dejarla coagular durante dos horas a temperatura ambiente y luego refrigerarla toda la noche, para entonces centrifugarla y separar los sueros. Los sueros de los hamsteres con una sola inoculación y los de los demás animales con una, dos, tres y cuatro inoculaciones fueron congelados $\mathrm{a}-40^{\circ} \mathrm{C}$ hasta su uso en las reacciones serológicas.

- Reacciones serológicas de inmovilización y de aglutinación de promastigotos de Leishmania spp.

$50 \mu 1$ de cada suero, en cada oportunidad, fueron diluidos serialmente com $50 \mu 1$ de sobrenadante del medio de cultivo NNN para preparar diluciones de $1: 2$ hasta $1: 2048$. Se prepararon suspensiones de promastigotos también con el sobrenadante del medio NNN, para obtener 100.000 parásitos por $\mathrm{ml}$.

$50 \mu 1$ de cada dilución de los sueros sin inactivar se mezclaron cuidadosamente con $50 \mu \mathrm{l}$ de la suspensión de parásitos, para una concentración de 5000 parásitos en el volumen final. La mezcla se incubó 30 minutos a temperatura ambiente $\left(22^{\circ} \mathrm{C}\right)$ e inmediatamente se tomó una gota del sistema entre lámina y laminilla para observarla con $450 \mathrm{X}$.

Se revisaron todas las diluciones para precisar la más alta en donde se observara la total inmovilización de los parásitos o la aglutinación de los mismos.

\section{II - Ensayos xenodiagnósticos con Lu. townsendi}

- Especies y cepas de parásitos

Empleamos tres especies de Leishmania mantenidas todas en hamsteres. Dos subespecies de L. mexicana, L.m. mexicana aislada por Herrer, Telford $\&$ Christensen (1971) de Oryzomys capito y otra L.m. amazonensis aislada en el sur de Venezuela de Lutzomyia flaviscutellata por Pifano, Romero \& Alvarez (1973); una cepa de L. braziliensis panamensis aislada de un caso clínico de la costa del Pacífico en Panamá y cuatro cepas de $L$. garnhami (HM, GV, JRV y JAP) aisladas de casos clínicos del estado Mérida, Venezuela. 


\section{- Infecciones experimentales en hamsteres}

Utilizamos seis hamsteres machos inoculados subcutáneamente con amastigotos de seis aislados de Leishmania spp. en la cara dorsal de la pata posterior izquierda. Las lesiones discretas o visibles, según la especie de los parásitos, no tuvieron más de 30 días de evolución y produjeron hipertrofias hasta de $9,0 \mathrm{~mm}$ de diámetro.

\section{- Infecciones experimentales con Holochilus venezuelae y Sigmodon hispidus}

Los roedores provinieron de una zona no endémica para leishmaniasis en el llano centro-occidental venezolano, y fueron inoculados subcutáneamente con 250.000 promastigotos de una cepa de L. garnhami (JAP), aislada de un caso clínico de los Andes venezolanos. Un Sigmodon NO 1 recibió cinco inoculaciones en puntos equidistantes en la cara dorsal de la cola; otro No 2 fue inoculado similarmente en la cola y en la cara dorsal de las patas posteriores; otro No 3 fue inoculado, además, en las dos patas anteriores. Un Holochilus N $\mathrm{N}^{\mathrm{O}} 1$ fue similarmente inoculado en la cola y patas posteriores y otro ejemplar Nớ 2 recibió inóculos en la cola y en las cuatro patas. Los cinco animales fueron utilizados cuatro meses después de inoculados, cuando la mayoría de los sitios de inoculación mostró úlceras, alopecías o edemas perceptibles.

\section{- Captura, mantenimiento e infección de flebótomos}

Los insectos (Lutzomyia townsendi) fueron capturados tras ser atraídos con cebo luminoso hacia una trampa de Shannon, durante las noches, en la localidad de Calderas a $12 \mathrm{~km}$ de la ciudad de Trujillo, con una altitud de 1.360 m.s.n.m. y en una región donde no ha habido transmisión de leishmaniasis. De esta localidad, durante 14 meses, hemos examinado quincenalmente lotes de 50 o más ejemplares de $L u$. townsendi para estudios de paridad, sin hallar ningún ejemplar naturalmente infectado con flagelados de algún tipo; apenas hemos encontrado raras infecciones por Ascocystis chagasi (Scorza \& Carnevali, 1981). Los insectos fueron capturados por aspiración y se confinaron, en lotes de 50 , dentro de envases cilíndricos revestidos internamente con corcho (Fig. 1); así fueron alimentados con sacarosa al $50 \%$ y conservados dentro de una cava de plástico isoporo bajo un $90 \%$ de humedad y temperatura de $21^{\circ} \mathrm{C}$. En el caso de la infección de flebótomos sobre las patas de hamsteres, siempre a las $20: 00$ horas, estos roedores fueron anestesiados con $14.18 \mathrm{mg}$ de Nembutal en solución salina por vía intraperitoneal y una vez dormidos, se introdujo la pata infectada a través del orificio inferior del envase acorchado con los flebótomos, dejándolos ingurgitar durante 5 minutos al abrigo de la luz natural, tiempo suficiente para que casi todos picaran. Los insectos llenos de sangre se mantuvieron con solución de sacarosa.

En los casos de Sigmodon hispidus y de Holochilus venezuelae, infectados, con lesiones en la cola y extremidades, los roedores fueron anestesiados con 14-22 mg de Nembutal, e introducidos en posición decúbitodorsal en una jaula cilíndrica, fabricada con malla de nilon a prueba de flebótomos (Fig. 2) junto con 10 hasta 50 hembras de $L u$. townsendi; la jaula fue colocada dentro de una cava de isoporo, en la oscuridad, durante 15 minutos para luego separar los insectos ingurgitados, los cuales fueron confinados en envases cilíndricos especiales para recoger las deyecciones; los insectos picaron libremente al roedor.

\section{- Lectura de los xenodiagnósticos}

Setenta horas después de la ingesta infectante, los flebótomos ingurgitados fueron transferidos en lotes de 4 hasta 31 , a envases cilíndricos de $25 \mathrm{~mm}$ de diámetro, revestidos interiormente con una lámina de corcho y provistos en el extremo inferior de una lámina microscópica (porta-objetos), adherida con cinta plástica (Fig. 3). Los envases se conservaron verticalmente para permitir que las deyecciones de los insectos goteasen sobre la lámina. La primera lámina fue colocada a las 08.00 del tercer día después de la ingurgitación, y retirada 24 horas después cuando fue cambiada por una segunda y ésta por una tercera que también fue retirada 24 horas después, para obtener tres preparaciones cơn deyecciones de 84, 108 y 132 horas para cada envase cilíndrico. Inmediatamente des- 


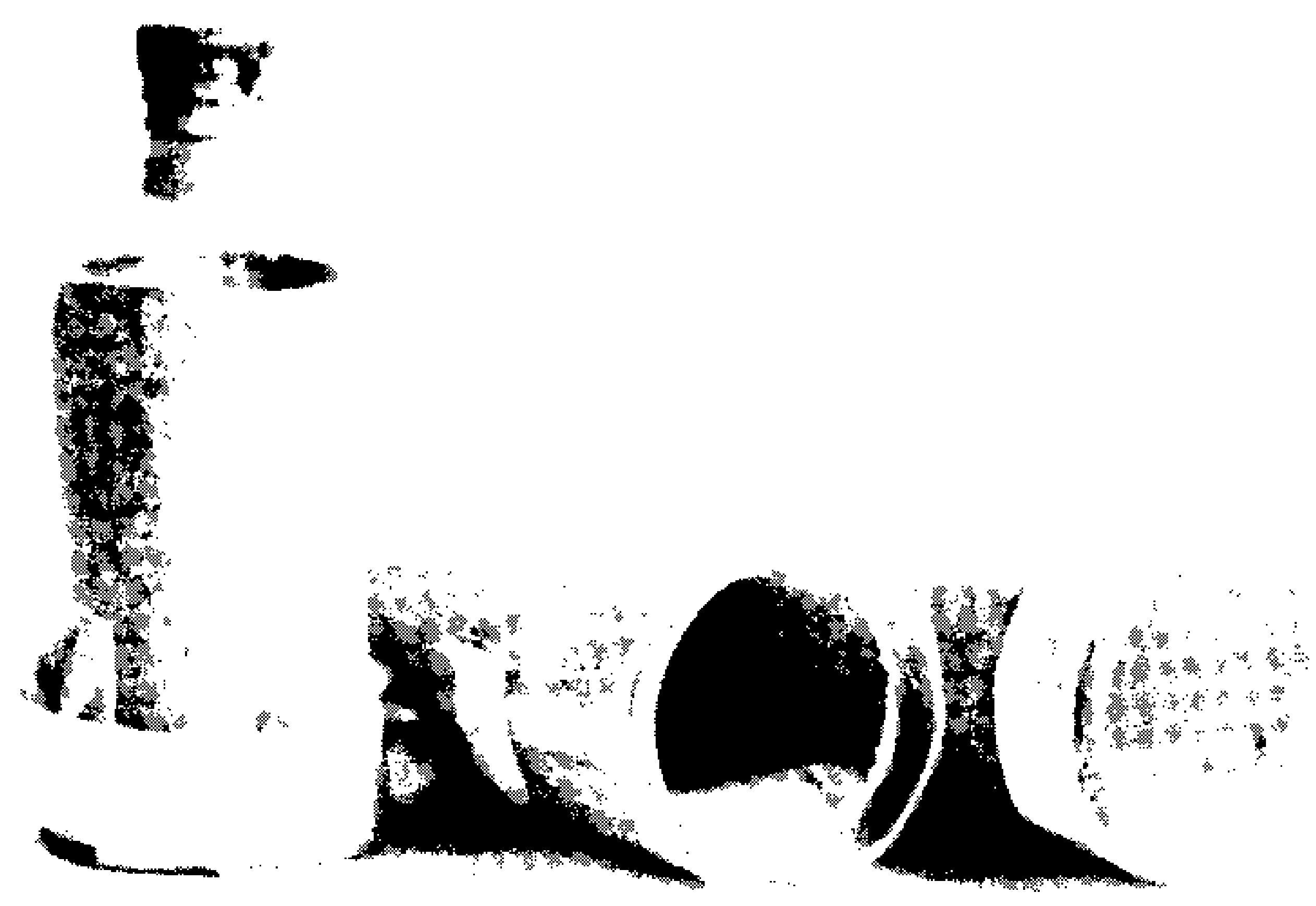

Fig. 1 - Envases de vidrio revestidos interiormente con lámina de corcho y cubiertos por malla de nilon para la captura, transporte y mantenimiento de $L u$. townsendi.

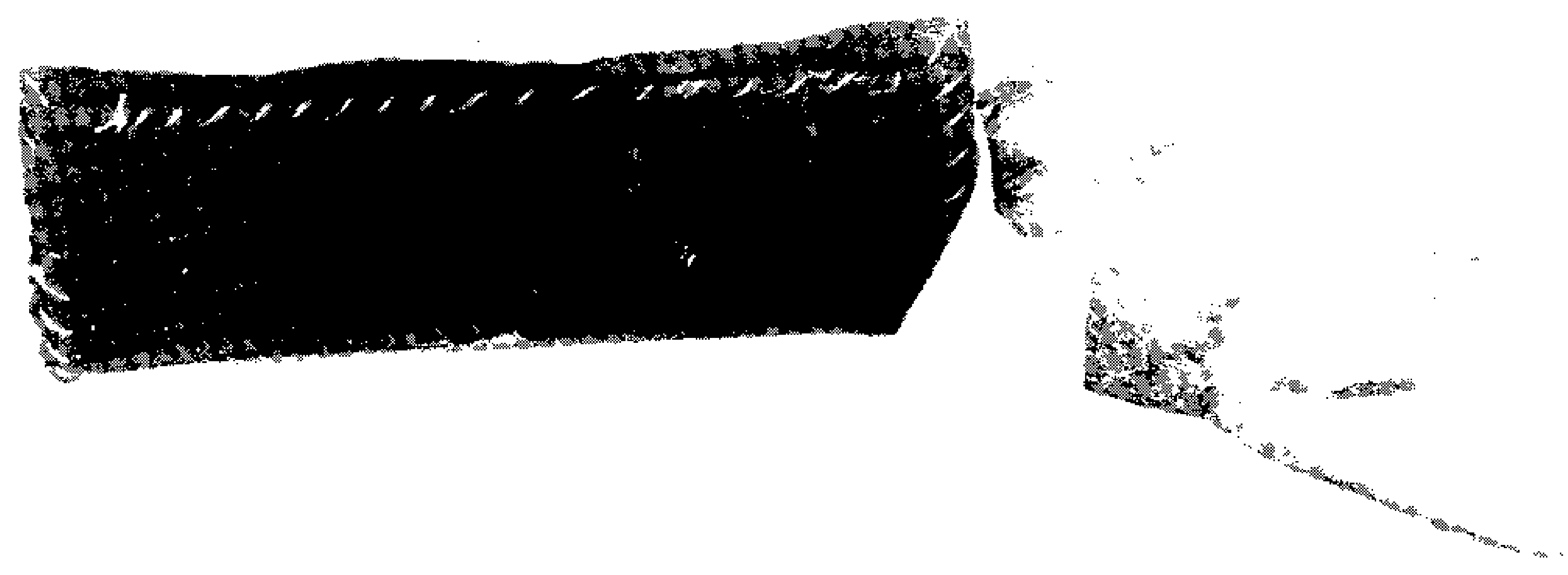

Fig. 2 - Jaula con malla de nilon y tela para la alimentación de Lu. townsendi sobre Holochilus o Sigmodon experimentalmente infectados con Leishmania spp.

pués de retiradas, se contaron las gotitas de deyecciones in coloras brillantes, y también a las oscuras u opacas en el área circular, y luego las láminas fueron fijadas con metanol y coloreadas con Giemsa al $5 \%$, en solución tamponada de fosfato $\mathrm{M} / 200$ a $\mathrm{pH} 7.2$ durante una hora. Bajo la lupa X 50 y también con aumento $450 \mathrm{X}$ se examinaron las deyecciones y se verificó la presencia de gotitas con promastigotos excretados. Finalmente, se contó a los insectos sobrevivientes, y se los disecó individualmente para verificar la presencia de haptomonas en la válvula estomodeal (faringe) o en el triángulo pilórico, según las especies de Leishmania. 

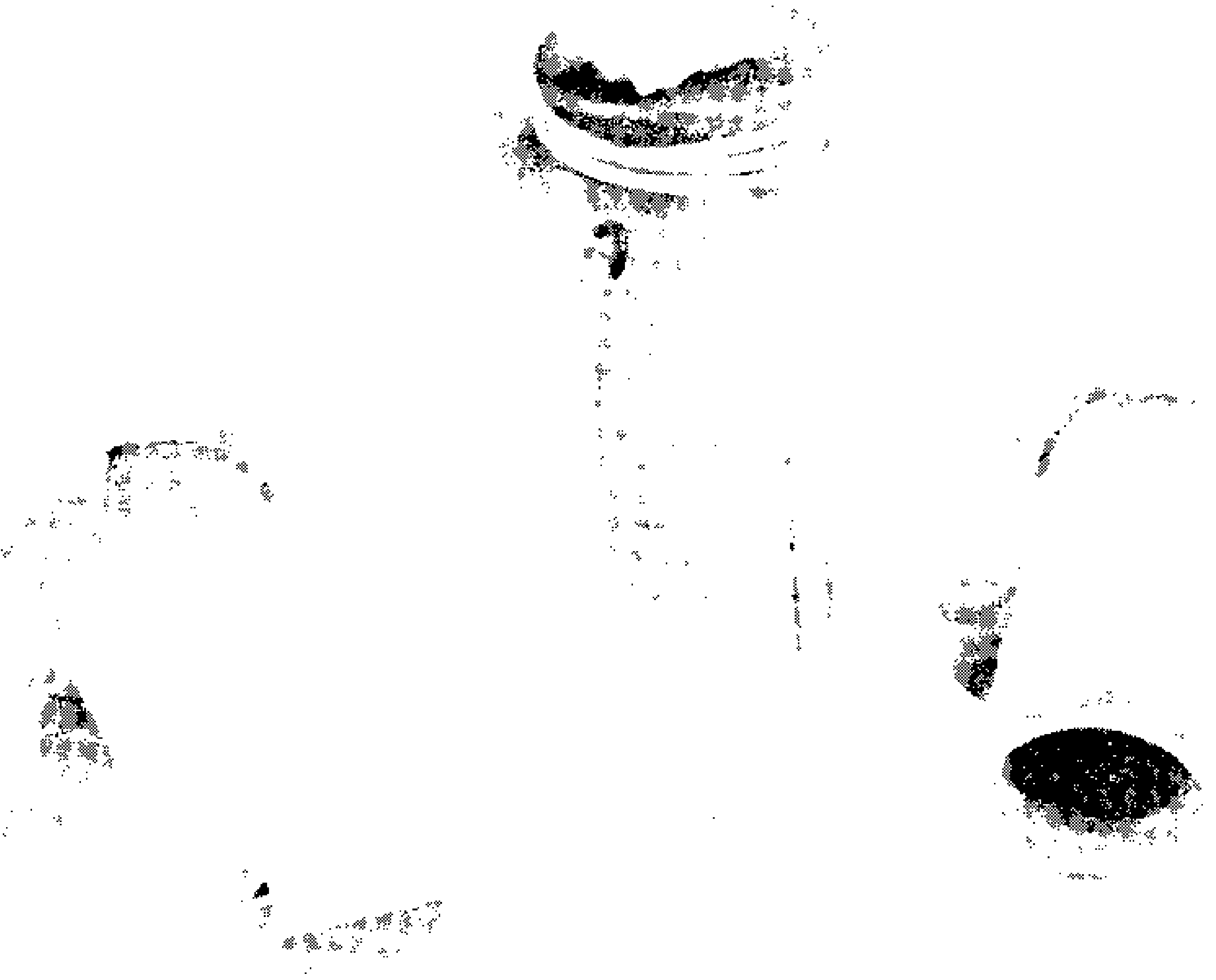

Fig. 3 - Cilindros para las lecturas de los xenodiagnósticos con $L u$. townsendi. Detalles de la fijación de los porta-objetos para recoger las deyecciones de los flebótomos.

\section{RESULTADOS}

\section{Ensayos serológicos}

La inoculación de los animales con las distintas cepas de leishmanias y las repetidas cardiopunturas en los mismos, produjo una mortalidad que no podemos atribuir a uno o otro factor por separado. En el Cuadro I informamos sobre el número de animales sobrevivientes al final del experimento. De los animales inoculados con Leishmania mexicana mexicana, dos ejemplares de $D$. marsupialis fallecieron después de la segunda cardiopuntura y tres $H$. venezuelae después de la tercera. De los animales inoculados con la cepa HM uno falleció después de la segunda cardiopuntura, otro después de la tercera y dos tras la cuarta. Es importante señalar, sin descartar el efecto traumático de la extracción de sangre, que los animales inoculados con la cepa JAP soportaron mejor la manipulación, ya que de catorce ejemplares uno solo falleció.

\section{CUADRO I}

Mortalidad de los animales experimentales después de cada inoculacion con Leishmania spp. (inoculados/sobrevivientes)

\begin{tabular}{l|c|c|c}
\hline Espécies de mamiferos & L.m.m. & J.A.P. & H.M. \\
\hline Cricetus auratus & $5 / 5$ & $5 / 5$ & $5 / 5$ \\
Didelphis marsupialis & $4 / 2$ & $4 / 4$ & $4 / 4$ \\
Holochilus venezuelae & $5 / 2$ & $5 / 4$ & $5 / 1$ \\
\hline
\end{tabular}


De las pruebas serológicas con promastigotos vivos de cultivo, y para los objetivos que nos hemos propuesto en este trabajo, la de aglutinación ofreció resultados más consistentes y de alguna aplicación como prueba presuntiva para informarmos cuando un mamífero, en este caso un cricétido o un marsupial habían recibido una carga antigénica viva de Leishmania spp. Expondremos en primer lugar, por lo tanto, los resultados de este tipo de ensayo. En el hamster, animal escogido como patrón de comparación por su alta sensibilidad a los parásitos, los títulos normales de aglutinación disminuyen considerablemente a los diez días de su inoculación intradérmica, con cualquiera de las tres cepas de parásitos (Cuadro II).

\section{CUADRO II}

Variacion del reciproco de los titulos de aglutinación en los sueros de hamsteres normales y después de una unica inoculacion con Leishmania spp.

\begin{tabular}{|c|c|c|c|c|c|c|}
\hline \multirow{2}{*}{$\begin{array}{l}\text { Cepa del } \\
\text { parásito }\end{array}$} & \multirow{2}{*}{\multicolumn{2}{|c|}{$\begin{array}{l}\bar{x} \text { de los titulos } \\
\text { sanos-inoculados }\end{array}$}} & \multicolumn{2}{|c|}{ Estadisticos } & \multirow{2}{*}{\multicolumn{2}{|c|}{$\begin{array}{c}\text { Discriminación } \\
\text { por la prueba } \\
\text { de Duncan }\end{array}$}} \\
\hline & & & $F$ & $P$ & & \\
\hline L.m.m. & 256 & 0 & 13,3 & 0,0065 & A & B \\
\hline J.A.P. & 115 & 64 & 1,3 & 0,28 & A & A \\
\hline H.M. & 230 & 96 & 2,5 & 0,52 & A & A \\
\hline
\end{tabular}

Con la cepa de L. mexicana mexicana la disminución del título es total, y se aprecian diferencias significativas entre el título relativamente alto de los animales no expuestos y los de aquellos que recibieron una dosis de promastigotos como inóculo. Con las otras dos cepas de L. garnhami (JAP y HM) las caídas de los títulos, aún cuando se observan, no son estadísticamente diferentes a las de los títulos de los mismos animales antes de las respectivas inoculaciones.

La $L$. mexicana mexicana exhibe un comportamiento similar cuando es inoculada en los $H$. venezuelae (Cuadro III) y en $D$. marsupialis (Cuadro IV). Las diferencias en los títulos de aglutinación, a partir de la primera inoculación, se mantienen en el curso de las inoculaciones siguientes, indicando que en los modelos "cricétido" y "marsupial" que reciben una o varias cargas antigénicas de este parásito, se inhibe o neutraliza la producción de anticuerpos aglutinantes. Con las otras cepas de parásitos, en $H$. venezuelae, ocurre un fenómeno similar aún cuando la reducción de los títulos no es tan dramática como la ocurrida con la exposición a $L . m$. mexicana; las diferencias entre los títulos de los animales normales y los de los expuestos, sin embargo, son altamente significativos $(\mathrm{P}=0,0001$ y 0,004 para $\mathrm{JAP}$ y HM respectivamente). Con D. marsupialis y L. garnhami no se aprecian cambios en los títulos de aglutinación de promastigotos y las variaciones son tan impredecibles que es imposible, a través de esta prueba, sugerir cuando un $D$. marsupialis ha estado o no expuesto a este parásito.

En conclusión, titulos bajos con la prueba de aglutinación de promastigotos de cultivo, en dos géneros diferentes de cricétidos, podrían considerarse indicadores de exposición de estos animales a dos especies de Leishmania; los animales que han recibido una o varias cargas antigénicas, o no aglutinan o poseen bajos títulos de aglutinación. Una cepa de $L$. m. mexicana, constantemente, en los tres tipos de animales, incluyendo a $D$. marsupialis, produjo una abrupta caída o disminución en los títulos de las aglutininas normales.

Los resultados de los ensayos de inmovilización se presentan en los Cuadros V, VI y VII, respectivamente para hamsteres, $H$. venezuelae y $D$. marsupialis. En ningún caso se registraron deferencias consistentes y significativas entre los títulos de inmoviliza- 


\section{CUADRO III}

Variaciones del reciproco de los titulos de aglutinacion en $H$. venezuelae normales y después de cuatro inoculaciones con Leishmania spp. con discriminaciones por la prueba de Duncan

\begin{tabular}{|c|c|c|c|c|c|c|c|}
\hline \multirow[t]{2}{*}{$\begin{array}{l}\text { Cepa del } \\
\text { parásito }\end{array}$} & \multicolumn{5}{|c|}{$\begin{array}{c}\bar{x} \text { de los titulos antes y después } \\
\text { de las inoculaciones }\end{array}$} & \multicolumn{2}{|c|}{ Estadisticos } \\
\hline & 0 & $l$ & 2 & 3 & 4 & $\bar{F}$ & $P$ \\
\hline \multirow[t]{2}{*}{ L.m.m. } & 2.253 & 0 & 0 & 0 & 0 & 7,56 & 0,0007 \\
\hline & $\mathbf{A}$ & B & B & B & B & & \\
\hline \multirow[t]{2}{*}{ J.A.P. } & 1.434 & 742 & 179 & 102 & 67 & 17,26 & 0,0001 \\
\hline & A & B & $\mathrm{C}$ & $\mathrm{C}$ & $\mathrm{C}$ & & \\
\hline \multirow[t]{2}{*}{ H.M. } & 563 & 0 & 128 & 26 & 64 & 5,5 & 0,0037 \\
\hline & A & B & B & B & B & & \\
\hline
\end{tabular}

\section{CUADRO IV}

Variaciones del reciproco de los titulos de aglutinacion en $D$. marsupialis normales, y después de cuatro inoculaciones con Leishmania spp., con sus discriminaciones por la prueba de Duncan

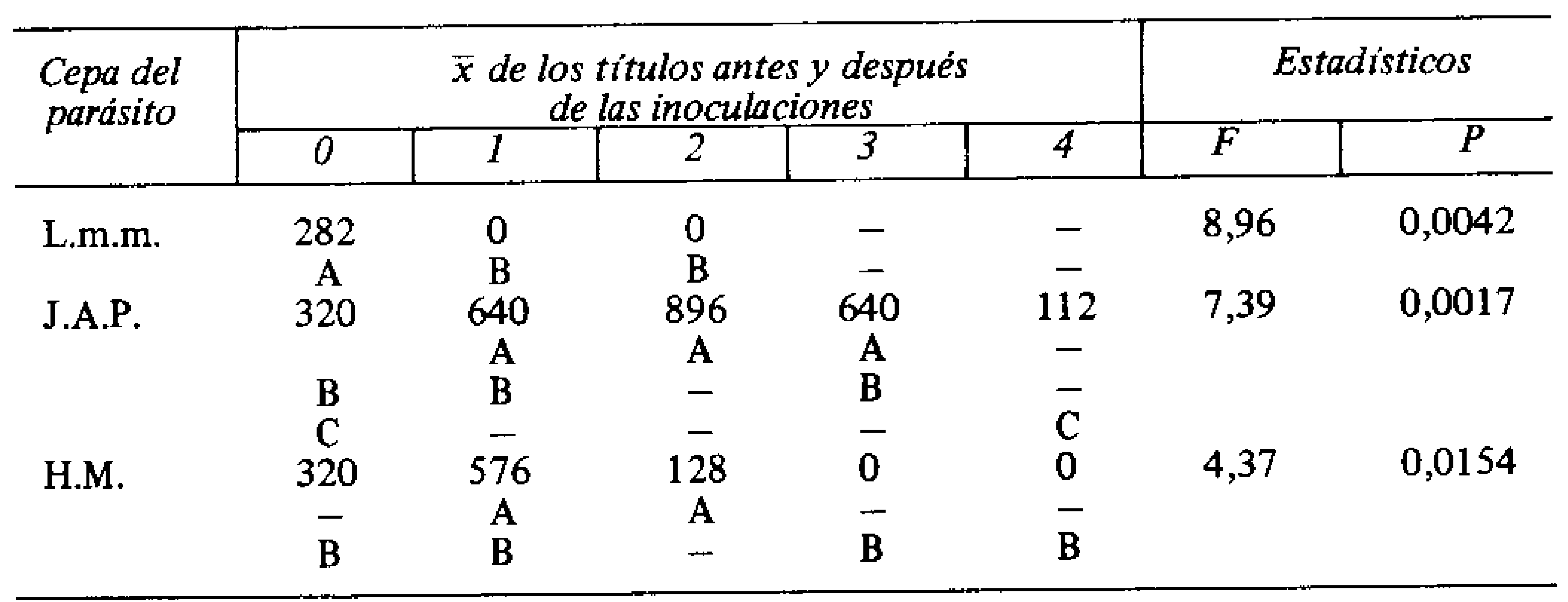

ción de los animales normales y los expuestos a $L . m$. mexicana y L. garnhami. En los hamsteres parece producirse una respuesta de tipo humoral a los 10 días después de la inoculación con los parásitos, y esa respuesta es significativamente mayor frente a $L . m$. mexicana que a $L$. garnhami. No ocurre lo mismo con $H$. venezuelae y $D$. marsupialis en donde las variaciones de los títulos, después de la primera y con las siguientes inoculaciones, son completamente impredecibles; en algunas circunstancias los títulos parecen aumentar, como son los casos de D. marsupialis y $L$. garnhami, no registrándose diferencias estadísticamente significantes.

\section{Xenodiagnósticos en infecciones experimentales}

Con la finalidad de precisar la tasa de eliminación de excretas por los flebótomos experimentalmente ingurgitados sobre hamsteres infectados, y evidenciar la presencia de 


\section{CUADRO V}

Variaciones del reciproco de los titulos de inmovilización en los sueros de hamsteres normales y después de una unica inoculacion con Leishmania spp.

\begin{tabular}{|c|c|c|c|c|c|c|}
\hline \multirow{2}{*}{$\begin{array}{l}\text { Cepa del } \\
\text { parásito }\end{array}$} & \multirow{2}{*}{\multicolumn{2}{|c|}{$\begin{array}{l}\bar{x} \text { de los titulos } \\
\text { sanos - inoculados }\end{array}$}} & \multicolumn{2}{|c|}{ Estadisticos } & \multirow{2}{*}{\multicolumn{2}{|c|}{$\begin{array}{c}\text { Discriminación } \\
\text { por la prueba } \\
\text { de Duncan }\end{array}$}} \\
\hline & & & $F$ & $P$ & & \\
\hline L.m.m. & 128 & 614 & 7,54 & 0,02 & A & B \\
\hline J.A.P. & 13 & 18 & 0,60 & 0,46 & A & A \\
\hline H.M. & 11 & 179 & 3,26 & 0,11 & A & A \\
\hline
\end{tabular}

\section{CUADRO VI}

Variaciones del reciproco de los titulos de inmovilización en los sueros de $H$. venezuelae normales y después de cinco inoculaciones con Leishmania spp. con discriminaciones por la prueba de Duncan

\begin{tabular}{|c|c|c|c|c|c|c|c|}
\hline \multirow[t]{2}{*}{$\begin{array}{l}\text { Cepa del } \\
\text { parásito }\end{array}$} & \multicolumn{5}{|c|}{$\begin{array}{c}\bar{x} \text { de los titulos antes y después } \\
\text { de las inoculaciones }\end{array}$} & \multicolumn{2}{|c|}{ Estadisticos } \\
\hline & 0 & 1 & 2 & 3 & 4 & $F$ & $\bar{P}$ \\
\hline L.m.m. & $\begin{array}{l}45 \\
\mathrm{~A}\end{array}$ & $1 \xi$ & $\begin{array}{l}11 \\
\mathrm{~A}\end{array}$ & $\begin{array}{c}819 \\
B\end{array}$ & $\begin{array}{c}819 \\
B\end{array}$ & 1,88 & 0,150 \\
\hline J.A.P. & 70 & 7 & 48 & 20 & 34 & 2,06 & 0,124 \\
\hline H.M. & $\begin{array}{c}\text { A } \\
563 \\
\text { B }\end{array}$ & $\begin{array}{l}\mathrm{A} \\
0 \\
\mathrm{~A}\end{array}$ & $\begin{array}{c}\mathrm{A} \\
103 \\
\mathrm{~B}\end{array}$ & $\begin{array}{l}\text { A } \\
26 \\
\mathrm{~B}\end{array}$ & $\begin{array}{l}\mathrm{A} \\
64 \\
\mathrm{~B}\end{array}$ & 3,31 & 0,031 \\
\hline
\end{tabular}

\section{CUADRO VII}

Variaciones del reciproco de los titulos de inmovilización en $D$. marsupialis normales y después de cuatro inoculaciones con Leishmania spp., con discriminaciones por la prueba de Duncan

\begin{tabular}{|c|c|c|c|c|c|c|c|}
\hline \multirow[t]{2}{*}{$\begin{array}{l}\text { Cepa del } \\
\text { parásito }\end{array}$} & \multicolumn{5}{|c|}{$\begin{array}{c}\bar{x} \text { de los titulos antes y después } \\
\text { de las inoculaciones }\end{array}$} & \multicolumn{2}{|c|}{ Estadisticos } \\
\hline & 0 & $i$ & 2 & 3 & 4 & $F$ & $P$ \\
\hline L.m.m. & 51 & $\begin{array}{c}128 \\
\mathrm{~A}\end{array}$ & $\begin{array}{l}51 \\
\mathrm{~A}\end{array}$ & - & - & 2,20 & 0,153 \\
\hline J.A.P. & 64 & 80 & 288 & 288 & 24 & 5,80 & 0,0050 \\
\hline H.M. & $\begin{array}{l}B \\
36 \\
B\end{array}$ & $\begin{array}{c}\text { B } \\
272 \\
\text { B }\end{array}$ & $\begin{array}{c}\mathrm{A} \\
768 \\
\mathrm{~A}\end{array}$ & $\begin{array}{c}A \\
256 \\
B\end{array}$ & $\begin{array}{c}B \\
160 \\
B\end{array}$ & 12,37 & 0,0001 \\
\hline
\end{tabular}

promastigotos de Leishmania spp. en las mismas, utilizamos 187 hembras de Lu. townsendi que en once ensayos, en lotes desde 4 hasta 31 ejemplares, fueron continados en los envases cilíndricos especiales provistos de porta-objetos. En cada ensayo se retiraron tres láminas a las 84,108 y 132 horas que fueron expuestas durante 24 horas, cada una, para recibir deyecciones a partir de las 60 horas de la ingesta infectante. Con el número de 
deyecciones depositadas sobre las láminas y el número de flebótomos vivos contados cada vez que se retiraban las láminas, se determinó, aproximadamente, el número de deyecciones excretadas por flebótomo y se precisó, además, cuando comenzaron a eliminarse promastigotos.

En el Cuadro VIII presentamos los resultados con el número de flebótomos ingurgitados en cada uno de los once experimentos, el número de deyecciones por flebótomos a las 84,108 y 132 horas, el número de los insectos sobrevivientes, el porcentaje de mortalidad ocurrida en los 5-1/2 días después de la ingesta infectante y finalmente el número de flebótomos que mostraron flagelados en el tubo digestivo cuando fueron disecados.

\section{CUADRO VIII}

Aparicion de deyecciones positivas a promastigotos de Leishmania spp. En excretas de Lu. to wnsendi experimentalmente infectados, con indicacion de los porcentajes de mortalidad de insectos y el porcentaje de los mismos hallados positivos a Leishmanias.

(+ = número de gotitas de deyecciones positivas a promastigotos).

\begin{tabular}{|c|c|c|c|c|c|c|}
\hline \multirow{2}{*}{$\begin{array}{l}\text { Especie y cepa } \\
\text { de Leishmania }\end{array}$} & \multirow{2}{*}{$\begin{array}{l}\text { No inicial de } \\
\text { de flebótomos } \\
\text { ingurgitados }\end{array}$} & \multicolumn{3}{|c|}{ Deyecciones por flebótomos a las } & \multirow{2}{*}{$\begin{array}{l}\text { No de insectos } \\
\text { disecados } y \% \\
\text { de mortalidad }\end{array}$} & \multirow{2}{*}{$\begin{array}{l}N^{O} \text { de insectos } \\
\text { infectados } y \% \\
\text { de infecciones }\end{array}$} \\
\hline & & 84 & 108 & 132 hores & & \\
\hline $\begin{array}{l}\text { L. b. panomensis } \\
1 \text { Lbp } \\
2 \mathrm{Lbp} \\
3 \mathrm{Lbp}\end{array}$ & $\begin{array}{r}10 \\
4 \\
8\end{array}$ & $\begin{array}{l}13,6 \\
21,0 \\
17,0\end{array}$ & $\begin{array}{l}15,5+ \\
22,5+ \\
20,5+\end{array}$ & $\begin{array}{l}4,8-2+ \\
2,5-1+ \\
1,8-5+\end{array}$ & $\begin{array}{ll}9 & (10) \\
4 & \\
7 & (12,5)\end{array}$ & $\begin{array}{ll}1 & 110,01 \\
1 & 125,01 \\
2 & 128.61\end{array}$ \\
\hline $\begin{array}{l}\text { L. m. mexicano } \\
4 \text { L.m.m. }\end{array}$ & 8 & 15,3 & $11,3-$ & $10,6-4+$ & $7(12.5)$ & $1(14,3)$ \\
\hline $\begin{array}{l}\text { l. m. amazonens } \\
5 \text { L.m.a. }\end{array}$ & 15 & 14,8 & $12.3-$ & $11,1-6+$ & $14 \quad(6,7)$ & $1\{7,1\}$ \\
\hline $\begin{array}{l}\text { L. garnhami } \\
6 \mathrm{HM} \\
7 \mathrm{GV} \\
8 \mathrm{GV} \\
9 \mathrm{GV} \\
10 \mathrm{GV} \\
11 \mathrm{JRV}\end{array}$ & $\begin{array}{l}17 \\
18 \\
18 \\
31 \\
28 \\
25\end{array}$ & $\begin{array}{r}3,0 \\
14,4 \\
8,3 \\
12,9 \\
12,0 \\
14,0\end{array}$ & $\begin{array}{r}6.6- \\
13.6+ \\
9.6+ \\
11.5+ \\
11.5+ \\
11.8-\end{array}$ & $\begin{array}{r}8,25-9+ \\
8,7-15+ \\
12,4-11+\end{array}$ & $\begin{array}{ll}12 & (23) \\
12 & (33) \\
11 & (38,9) \\
31 & - \\
27 & (3,6) \\
13 & (48)\end{array}$ & $\begin{array}{ll}3 & (25) \\
6 & (50) \\
3 & (27,3) \\
5 & (16.1) \\
4 & (14.8) \\
1 & (15,4)\end{array}$ \\
\hline TOTALES & 187 & $\bar{x}: 13,3 \pm 2,15$ & $13,3 \pm 2.15$ & $7,61 \pm 1,9$ & $147(21,4)$ & $29 \quad(19,7)$ \\
\hline
\end{tabular}

Deyecciones positivas a promastigotos aparecieron entre las 84 y 108 horas después de la ingesta infectante en dos de las tres especies de Leishmania investigadas; 23 flebótomos alimentados sobre $L$. mexicana no excretaron promastigotos hasta las 108 horas de postingestión. Entre las 108 y 132 horas, se eliminan fecalmente promastigotos de $L$. braziliensis, $L$. mexicana y $L$. garnhami en las heces de $L u$. townsendi infectados. El porcentaje de flebótomos sobrevivientes y hallados infectados, por disección, varió desde 7.1 para un experimento con L. mexicana amazonensis hasta 50 en otro experimento con L. garnhami. De 187 flebótomos utilizados en once ensayos, sobrevivieron $147(78,6 \%)$ y el $19,7 \%$ de estos aparecieron infectados con la excepción de la cepa JRV de L. garnha$m i$, donde a pesar de haberse encontrado dos flebótomos positivos, no se detectó la excreción de promastigotos. En los diez experimentos restantes hubo concordancia entre la presencia de infecciones en algunos de los insectos y la eliminación de excretas con promastigotos. La técnica de lectura de xenodiagnóstico por examen microscópico de las deyecciones, permitió detectar hasta un flebótomo entre 15 que se alimentaron sobre un hamster infectado. El número de flebótomos utilizados en los ensayos varió desde 4 hasta 31 , y la mortalidad, probablemente por efecto de la densidad, pareció aumentar con el 
número de insectos confinados en los cilindros de defecación; en el experimento $\mathrm{N}^{0} 10$, donde se confinaron 28 insectos, sin embargo, la mortalidad fue menor a la que se registró en otros experimentos con menos de 15 flebótomos por envase.

Habiéndose demostrado la posibilidad de utilizar la técnica de xenodiagnóstico como lectura para el examen de las deyecciones de los flebótomos, la aplicamos seguidamente para detectar infecciones por Leishmania garnhami en Holochilus venezuelae y Sigmodon hispidus, experimentalmente infectados con la cepa JAP de L. gamhami.

La inoculación subcutánea de 250.000 promastigotos en la cola, en cualquiera de las patas o en la trompa de Holochilus o en la cola y patas de Sigmodon produjeron lesiones discretas, alopécicas o ligeramente hipertróficas a los 90 días de la inoculación; los frotes de las lesiones mostraron numerosos amastigotos en la dermis, y los parásitos se hallaron circunscritos al sitio de inoculación y en el área de las lesiones que siempre fueron limitadas en extensión.

Los xenodiagnósticos fueron positivos en cuatro de los cinco animales, en aquellos que fueron inoculados en la cola y también en las dos o cuatro extremidades. La lectura de los xenodiagnósticos, mediante la búsqueda de gotitas de excretas de flebótomos infectados con promastigotos no dieron resultados negativos falsos; de quince exposiciones de flebótomos a animales seguramente infectados, en once oportunidades (73\%) no se registraron infecciones en los flebótomos, lo cual indica que la técnica registra, sólo confiablemente, infecciones por Leishmania en un $27 \%$ de los casos, cuando las lesiones son múltiples y limitadas (Cuadro IX).

\section{CUADRO IX}

Xenodiagnósticos y excreción de flagelados por Lutzomyia townsendi ingurgitados sobre dos cricetinae experimentalmente infectados con la cepa "JAP" de L. gamhami

\begin{tabular}{|c|c|c|c|c|c|}
\hline $\begin{array}{c}\text { Animales } \\
\text { experimentales }\end{array}$ & $\begin{array}{c}\text { Sitios } \\
\text { inoculados* }\end{array}$ & $\begin{array}{c}\text { No de } \\
\text { cilindros }\end{array}$ & $\begin{array}{l}\text { Flebótomos } \\
\text { por cilindro }\end{array}$ & $\begin{array}{c}\text { No de deyecciones } \\
\text { positivas por } \\
\text { cilindro }\end{array}$ & $\begin{array}{l}\text { Flebotómos } \\
\text { infectados: } \% \\
\quad \text { por cilindro }\end{array}$ \\
\hline Sigmodon Nọ 1 & $\mathrm{C}$ & 1 & 18 & - & $0-$ \\
\hline \multirow[t]{2}{*}{ Sigmodon NO 2} & C y PP & 2 & 15 & - & $1(6,67)$ \\
\hline & & & 15 & - & $0-$ \\
\hline \multirow[t]{2}{*}{ Sigmodon Nọ 3} & $\mathrm{C}, \mathrm{PP}$ y $\mathrm{PA}$ & 2 & 15 & - & $0-$ \\
\hline & & & 19 & $4+$ & $1(5,2)$ \\
\hline \multirow[t]{4}{*}{ Holochilus $\mathrm{N}^{\mathrm{O}} \mathbf{1}$} & $C, P P$ y $P A$ & 4 & 15 & $2+$ & $1(6,67)$ \\
\hline & & & 15 & - & $0-$ \\
\hline & & & 17 & - & $0-$ \\
\hline & & & 22 & - & $0-$ \\
\hline \multirow[t]{6}{*}{ Holochilus N: 2} & $\mathrm{C}, \mathrm{PP}, \mathrm{PA}$ y $\mathrm{T}$ & 6 & 15 & - & $0-$ \\
\hline & & & 24 & $5+$ & $1(4,2)$ \\
\hline & & & 31 & - & $0-$ \\
\hline & & & 28 & - & $0-$ \\
\hline & & & 12 & - & $0-$ \\
\hline & & & 19 & - & $0-$ \\
\hline Total de flebótomos & & & 280 & & $4(1,43)$ \\
\hline
\end{tabular}

* = C: cola; PP: patas posteriores; PA: patas anteriores; $T$ : trompa.

\section{DISCUSION Y CONCLUSIONES}

La aglutinación de promastigotos de cultivo por los sueros de hamster, Didelphis marsupialis y de Holochilus venezuelae infectados experimentalmente con una cepa de 
Leishmania mexicana y dos cepas de L. garnhami (JAP y HM), parece estar asociada con modificaciones de la condición inmune durante el curso de la infección. La progresiva disminución de los títulos de aglutinación o la no aglutinación de los parásitos por los sueros de los animales que han recibido una o varias cargas antigénicas, parece indicar que estas infecciones por Leishmania spp desensibilizan al animal, lo que implica una supresión de la respuesta; esto se ha formulado para explicar las formas diseminadas de leishmaniasis cutánea difusa en donde parece producirse, más un dafio central en relación con el desarrollo de la respuesta celular específica a leishmania, que a nivel de la expresión periférica de esta respuesta (Bryceson, 1970 y Zuckerman, 1975). La diseminación cutánea desarrolada por $L$. enriett $i$ en cobayos, cuando han sido inmunosuprimidos con suero antilinfocitico (Bryceson \& Turk, 1971), o cuando la lesión primaria se produjo en la piel con drenaie interrumpido de linfocitos (Kadivar \& Soulsby, 1975), revela la deprivación de células $\mathrm{T}$, con disminución de la hipersensibilidad retardada y aumento en la severidad de la infección.

Recientemente Poulter \& Pearce (1980) reportaron que en cobayos destinados al mantenimiento de las cepas en el laboratorio, se establece una protección inmunocelular que después disminuye con la inmunosupresión del animal.

Es evidente que la presencia de los parásitos en el hospedador está condicionada por un mecanismo de defensa pre-existente, lo que explica la sobrevivencia, multiplicación y distribución de los parásitos.

La técnica de aglutinación de parásitos que hemos ensayado con los modelos hamster, $H$. venezuelae y $D$. marsupialis para el eventual despistaje de animales que podrían haber estado expuestos a infecciones por Leishmania spp. de la región endémica en que trabajamos, revela una variable información relacionada con los mecanismos básicos de defensa de los hospedadores. Garnham \& Humphrey (1969), advierten que existen evidencias de peso, de que una vez que la infección se inicia, el curso de la misma, en término de cronicidad y severidad queda determinada por la falta de mecanismos de defensa del hospedador; a conclusiones similares se ha llegado trabajando con ratones infectados con $L$. tropica (Preston et al, 1972, 1978); donde se han registrado niveles bajos de anticuerpos en el suero de los animales (Bryceson, Bray \& Dumonde, 1974); Radwanski et al (1974) por su parte, no han hallado asociación entre los títulos de anticuerpos y la recuperación de la infección, en tanto que Behfourouz, Rezai \& Gettner (1976), han registrado tal asociación, lo que si es claro, sin embargo, es que los títulos de anticuerpos demostrados por los métodos de hemaglutinación o de inmunoflourescencia fluctuan durante el curso de la enfermedad (Poulter, 1980).

Es bien conocido que el suero normal de varias especies de animales produce rápida inmovilización de promastigotos de Leishmania spp. (Urlich, Ortiz \& Convit, 1968). Recientes trabajos con suero de cobayos han demostrado que la actividad lítica del suero sobre los parásitos es termolábil, y puede ser abolida en presen cia de EDTA, lo que implica que tales lisis son complemento dependiente y se identifican con una fracción de IgM (Poulter \& Sundsmo, 1980).

En la búsqueda de reservorios silvestres de parásitos de los complejos "mexicana" y "braziliensis", sobresalen dos hechos fundamentales. En primer lugar, el hallazgo de estos parásitos en la sangre, como ha quedado demostrado cuando se han hecho hemocultivos o se han inoculados animales susceptibles, como el hamster, con sangre obtenida por cardiopunctura de roedores silvestres aparentemente sanos (Anonimo, 1958; Forattini, 1960 y Torrealba, Gomes-Nuñez \& Ulloa, 1972); en estos casos, roedores de los géne ros Proechimys, Kannabateomys, Cuniculus, Dasyprocta y Heteromys dieron hemocultivos positivos a promastigotos de Leishmania spp. En segundo lugar, el cultivo de trocitos de piel que no excluye la posibilidad de contaminación con sangre infectada, arroja también valiosa información; Herrer, Thatcher \& Johnson (1966) revelan hallazgos tan importantes como la presencia de L. hertigi en un $75 \%$ de Coendu rothschildi, inclusive con repeti- 
dos exámenes dentro de un período de cinco meses, aislamiento de cepas de L. mexicana por cultivo de piel de la cola en un $36 \%$ de 39 ejemplares de Oryzomys capito, e identificación de Choleopus hoffmanni y Bradypus infuscatus como reservorios de L. braziliensis en Panamá. Estos hechos están relacionados con los hábitos alimentarios de Phlebotominae que pican a los mamíferos, cuyas piezas bucales están adaptadas para producir pequeñas hemorragias en la dermis e ingerir sangre de las mismas (Lewis, 1975). La consideración de los hechos anotados, bajo la luz de la alta susceptibilidad de los flebótomos mastozoófilos del Neotrópico a la infección con casi cualquiera cepa de Leishmania, hace altamente aprovechable la técnica del xenodiagnóstico con flebótomos en la investigación de reservorios silvestres de Leishmania en América. Carnevali \& Scorza (1976) evidenciaron el desarrollo de una cepa de $L$. mexicana en $L u$. townsendi y en este mismo trabajo que ahora presentamos, se demuestra la susceptibilidad de esta misma especie de flebótomo a tres diferentes especies de Leishmania que producen lesiones clínicas.

El porcentaje de $L u$. townsendi que se infectan cuando se ingurgitan libremente sobre un animal seguramente infectado, como en los casos de $H$. venezuelae y $S$. hispidus, es generalmente bajo y no sobrepasa el $7 \%$ en lotes de 15 hasta 31 flebótomos disecados. Estos porcentajes de infecciones experimentales son siempre superiores a los que se registran normalmente en disecciones de flebótomos mastozoófilos capturados en zonas endémicas de leishmaniasis con activa transmisión; excepcionales altos valores registraron Biagi, Biagi \& Beltram (1965) y Lainson, Ward \& Shaw (1976), de 6,0 y 7,3\% para Lu. olmeca y Lu. umbratilis respectivamente, pero esta no es la regla; generalmente los porcentajes no alcanzan al $0,5 \%$. Esto sugiere la posibilidad de usar hembras silvestres, de zonas no endémicas, particularmente las fototácticas que son atraídas por cebos luminosos, aunque la colonización de algunas especies neotropicales, particularmente Lu. gomezi y Lu. serrana (Johnson \& Hertig, 1961), Lu. longipalpis (Sherlock \& Sherlock, 1959) y Lu. flaviscutellata (Ward, 1977) no parece ofrecer serias dificultades, Lu. townsendi es colonizable en condiciones de laboratorio, esta especie va actualmente por la cuarta generación. Sin embargo, creemos que es perfectamente posible utilizar $L u$. townsendi silvestres, siempre y cuando procedan de localidades no endémicas y se incluyan siempre, como control de la "limpieza" del vector, lotes no menores de 50 hembras que podrían ingurgitarse sobre hamsteres normales y ser verificados por la misma técnica de lectura que ahora describimos.

Quienes se han ocupado de la epidemiología de la leishmaniasis tegumentaria en la Región Neotropical, saben cuán endiablado y complicado es el estudio de la cadena biológica que eventualmente conduce a la aparición de casos humanos que, por lo general, tienen el carácter de accidentes de baja probabilidad, aunque suelen presentarse en forma de brotes epidémicos. La excelente revisión de Lainson \& Shaw (1978) sobre el papel de los flebótomos incriminados como vectores y de los distintos mamíferos silvestres, usualmente considerados reservorios, revela el grado de tal complicación. Pocos trabajos tienen la seriedad sistemática de los producidos por Shaw \& Lainson (1972) en sus estudios longitudinales sobre las relaciones entre un vector, que usualmente no ataca al hombre como Lu. flaviscutellata y un roedor que padece la infección como Oryzomys capito, para el mantenimiento de la $L$. mexicana amazonensis, o los del grupo de Herrer en Panamá (Herrer, Telford \& Christensen, 1971; Herrer \& Christensen, 1975) sobre reservorios en la región del istmo. En Brasil, Forattini (1960) ha contribuido también grandemente a la investigación de reservorios.

Un programa sistemático de trampeo para pequeños mamíferos, en un área endémica de leishmaniasis tegumentaria del pie de monte de los Andes venezolanos (Soriano, 1977) puede proporcionar, en un semestre (Febrero-Julio, 1976) y con cien trampas por mes, más de quinientos animales con representantes de Sigmodon alstoni, Zygodontomys microtinus, Proechimys guyannensis, Heteromys anomalus, Marmosa robinsoni, Monodelphis brevicaudata y Didelphis marsupialis, todos ellos con la excepción de Sigmodon sp. y Monodelphis sp., señalados como reservorios de L. mexicana amazonensis, L. m. pifanoi y L. m. aristedesi y L. braziliensis braziliensis (Zuckerman \& Lainson, 1977; Lainson \& 
Shaw, 1978). Entre estos roedores y marsupiales, Proechimys se le ha hallado infectado con L. mexicana sin exhibir lesiones aparentes o inaparentes (Anonimo, 1956); Heteromys anomalus ha revelado infecciones crípticas por $L$. m. amazonensis, tras la inoculación de su sangre en hamsteres (Torrealba et a1, 1972) y D. marsupialis por cultivo o inoculación de vísceras (Lainson \& Shaw, 1973) o por xenodiagnóstico con Lu. townsendi (Scorza, 1981).

El ejemplo de trampeo citado para una localidad en la región endémica, revela la necesidad de ensayar metodologías expeditas y económicas que con escasos recursos de personal y ante la presencia de gran número de animales silvestres capturados, temporalmente permitan descartar a aquellos animales que, no exhibiendo lesiones no evidencien indicios de haber estado en contacto con el parásito o lo alberguen en forma críptica.

Las dos técnicas que hemos puesto a prueba con modelos experimentales presentan esas ventajas. La cardiopuntura para la extracción de suero para ensayos de aglutinación pueden servir también para hacer hemocultivos y producir, al menos presumiblemente en Cricétidos como Heteromys, Oryzomys, Akodon, Sigmodon y Echimidos como Proechimys indicios de infecciones por Leishmania spp. de la región endémica en que trabajamos. El xenodiagnóstico con 50 ejemplares de Lu. townsendi y su técnica de lectura indirecta, tal como lo proponemos, puede confirmar la condición real de reservorio de un animal presumido como tal. En estudios epidemiológicos no basta hallar lesiones con amastigotos de Leishmania sp. sino precisar que tales parásitos pueden circular a través de la cadena de vectores, en esta caso $L u$, townsendi, que es un insecto de alta susceptibilidad para las tres especies de Leishmania presentes en los Andes venezolanos (Carnevali \& Scorza, 1981).

Las pruebas de aglutinación de promastigotos con sueros de dos cricétidos, uno doméstico y otro silvestre, indican claramente su aplicación para la investigación de otros roedores relacionados, que presumiblemente hayan sido picados por flebótomos infectados. Si bien es cierto que en muchos casos la inoculación con jeringas de formas promastigotos de flebótomos no siempre producen infecciones patentes, no es menos cierto que escaso número de promastigotos de cultivo de cepas recientemente cultivadas, producen siempre infecciones en hamsteres. En cuanto a los resultados de las inoculaciones en Holochilus venezuelae y Sigmodon hispidus, estos serán presentados en una comunicación separada (Scorza \& Scorza, 1981 ).

En conclusión, los resultados de la exploración del modelo hamster, Holochilus venezuelae y Didelphis marsupialis, en el despistaje de animales no expuestos a cargas de Leishmania spp. indican la utilidad de las técnicas de aglutinación de promastigotos vivos con sueros frescos y del xenodiagnóstico con $\mathrm{Lu}$. townsendi, mediante la lectura por inspección de las deyecciones de los mismos, en la investigación de muestras poblaciones de pequeños mamíferos para estudios epidemiológicos de la leishmaniasis cutánea en los Andes de Venezuela.

\section{SUMMARY}

Presumptive and confirmative techniques for searching mammals which could be reservoirs for Leishmania parasites from man are described.

The changes of immobilising and agglutinating titers for promastigotes from culture by sera from normal and exposed mammals after single or repeated intradermal inoculation of promastigotes are described. A fall in titers of agglutination is observed in 
sera from hamsters, Holochilus venezuelae and Didelphis marsupialis after inoculation with $L$. mexicana mexicana from Panama and L. garnhami from the Venezuelan Andes region. The nature of this phenomenon is discussed.

Xenodiagnoses were made with Lutzomyia townsendi on Holochilus venezuelae and Sigmodon hispidus experimentally infected with $L$. mexicana mexicana, L. mexicana amazonensis, $L$. braziliensis and $L$. garnhami. The tests were read by means of microscope examination of stained faeces excreted by sandflies between 108 to 132 hours after feed. ing on infected animals. Positive results were obtained in $23 \%$ of experiments using mammals with localized lesions, allowing sandflies to feed freely on anesthetized animals with one to several localized lesions.

\section{AGRADECIMIENTOS}

Al Lcdo, Danilo Aguero por los animales silvestres; al Lcdo. Ernesto Rodríguez M. Sc. por su colaboración en el tratamiento estadístico. Al Centro de Computación de la ULA. A los Técnicos J.C. Márquez y Maritza Rondón por sus ayudas de campo y laboratorio. Al Lcdo. Elio Moreno por su permanente ayuda. A los Técnicos del Grupo de Investigaciones Parasitológicas "José Francisco Torrealba" por su colaboración y a la Srta. Irlanda Márquez por la copia del manuscrito.

\section{REFERENCIAS BIBLIOGRAFICAS}

ALLAIN, D.S. \& KAGAN, I.G., 1975. A direct agglutination test for leishmaniasis. Amer. J. Trop. Med. \& Hyg.. $24: 232-236$.

ANONIMO, 1956. Reports of Gorgas Memorial Laboratory. U.S. Government Printing Office, Washington, D.C., pp. 10-11.

ANONIMO, 1958. The thirtieth annual report of the work and operation of the Gorgas Memorial Laboratory, covering the fiscal year ended June 30,1957. U.S. Government Printing Office, Washington, D.C. p. 12 .

BEHFOUROUZ, N.; REZAI, H.R. \& GETTNER, S., 1976. Application of immunofluorescence to detection on antibody in Leishmania infection. Ann. Trop. Med. \& Parasit., $70: 293-299$.

BIAGl, F.; BIAGI, A.M.B. \& BELTRAN, N.F., 1965. Phlebotomus flaviscutellatus, transmisor natural de Leishamania mexicana. Prensa Méd. México, $30: 267-272$.

BRADLEY, D.J., 1972. Regulation of parasite populations. A general theory of the epidemiology and control of parasitic infections. Trans. Roy. Soc. Trop. Med. \& Hyg., 61 :697-708.

BRYCESON, A.D.M., 1970. Diffuse cutaneous leishmaniasis in Ethiopia. III. Immunological studies. Trans. Roy. Soc. Trop. Med. \& Hyg., $64: 380-387$.

BRYCESON, A.D.M. \& TURK, J.L., 1971. The effect of prolonged treatment with antilymphocyte serum on the course of infections with BCG and Leishmania enrietti in the guinea-pig. J. Pathol., $104: 153-165$.

BRYCESON, A.D.M.; BRAY, R.S. \& DUMONDE, D.C., 1974. Experimental cutaneous leishmaniasis. IV. Selective suppression of cell-mediated immunity during the response of guinea pigs to infection with Leishmania enrietti. Clin. Exp. Immunol., $16: 189-208$.

CARNEVALI, M. \& SCORZA, J.V., 1976. Infección experimental de Lutzomyia townsendi (Ortiz, 1959) con una cepa venezolana de Leishmania braziliensis. Bol. Dir. Malar. y San. Amb., 16 :333-343.

CARNEVALI, M. \& SCORZA, J.V., 1981. Factores dérmicos que condicionan la infección de Lutzomyia townsendi (Ortiz, 1959) por Leishmania spp. de Venezuela. En prensa. 
CHRISTENSEN, H.A. \& HERRER, A., 1972. Detection of Leishmania braziliensis by xenodiagnosis. Trans. Roy. Soc. Trop. Med. \& Hyg., $66: 798-799$.

CHRISTENSEN, H.A. \& HERRER, A., 1977. The use of phlebotomine sandflies in xenodiagnosis. En: Ecologie des Leishmanioses. Colloques Internationaux du Centre National de la Recherche Scientifique. C.N.R.S. (Eds.). 129-230 pp.

FORATTINI, O.P., 1960. Sobre os reservatórios naturais de leishmaniose tegumentar americana. Rev. Inst. Med. trop. S. Paulo., 2 :195-203.

GARNHAM, P.C.C. \& HUMPREY, J.H., 1969. Problems in leishmaniasis related to immunology. Curr. Top. Microbiol. Immunol., $48: 29-42$.

HERRER, A.; THATCHER, V.E. \& JOHNSON, C., 1966. Natural infections of Leishmania and trypanosomes demonstrated by skin culture. J. Parasitol, 52 :954-957.

HERRER, A. \& TELFORD, S.R., 1969. Leishmania braziliensis isolated from sloths in Panama. Science, $164: 1419-1420$.

HERRER, A.; TELFORD, S.R. \& CHRISTENSEN, H.A., 1971. Enzootic cutaneous leishmaniasis in eastern Panama. I: Investigation of the infection among forest mammals. Ann. trop. Med. \& Pa. rasit., $65: 349-358$.

HERRER, A.; CHRISTENSEN, H.A. \& BAUMER, R.J., 1973. Reservoir hosts of cutaneous leishmaniasis among Panamanian forest mammals. Amer. J. trop. Med. \& Hyg., $22: 585-591$.

HERRER, A. \& CHRISTENSEN, H.A., 1975. Infrequency of gross skin lesions among Panamanian forest mammals with cutaneous leishmaniasis. Parasitol, 71 :87-92.

JOHNSON, P.T. \& HERTIG, M., 1961. The rearing of Phlebotomus sandflies. II. Development and behaviour of Panamanian sandflies in laboratory culture. Ann. Entomol. Soc. Amer., 54:764-766.

KADIVAR, D.M.H. \& SOULSBY, E.J.L., 1975. Model for disseminated cutaneous leishmaniasis. Science. $190: 1198$.

KLINGLER, I.J., 1925. The cultural and serological relationship of Leishmania. Trans. Roy. Soc. trop. Med. \& Hyg., $19: 330-335$.

LAINSON, R. \& SHAW, J.J., 1973. Leishmanias and leishmaniasis of the New World, with particular reference to Brazil. Bull. Pan Amer. Hlth. Org., V7, (4), 1.

LAINSON, R.; WARD, R.D. \& SHAW, J.J., 1976. Cutaneous leishmaniasis in North Brazil: Lutzomyia anduzei as a major vector. Trans. Roy. Soc. trop. Med. \& Hyg., $70: 171-172$.

LAINSON, R. \& SHAW, J.J., 1978. The role of animals in the epidemiology of South American leishmaniasis. En Biology of the Kinetoplastida, vol. II, ed. Lumsden \& Evans. Acad. Press., 2-116 pp.

LEWIS, D. J., 1975. Functional morphology of the mouth parts in New World phlebotominae sandflies (Diptera: Psychodidae). Trans. Roy. Entomol. Soc. London., $126: 497-532$.

PEDROSO, A.M., 1913. Leishmaniose local do cão. Ann. Paul. Med. Cirurg., I :33-39.

PIFANO, F.C., 1940. La leishmaniasis tegumentaria en el Estado Yaracuy, Venezuela. Rev. Policlinica. Caracas, $9: 3639-3658$.

PIFANO, F.C., 1960. Aspectos epidemiológicos de la leishmaniasis tegumentaria en la región neotrópica, con especial referencia a Venezuela. Arch. Ven. Med. trop. \& Parasit. Med., $3: 3161$.

PIFANO, F.C.; ROMERO, J. \& ALVAREZ, A., 1973. Comprobación de una cepa de Leishmania dermotropa en Phlebotomus flaviscutellata Mangabeira, 1942 de la Sierra Parima, Territorio Federal Amazonas, Venezuela. Arch. Ven. Med. trop. \& Parasit. Med., 5 :145-167.

POULTER, L.W., 1980. Mechanisms of immunity to Leishmaniasis. Afr. J. Clin. Exp. Immunol., I $: 121-130$. 
POULTER, L.W. \& PEARCE, M.T., 1980. Mechanisms of immunity to leishmaniasis. III. The development and decay of resistance during metastatic disease. Clin. Exp. Immunol. In Press.

POULTER, L.W. \& SUNDSMO, J.S., 1980. Mechanisms of immunity to leishmaniasis. IV. Significance of complement activity in resistance to leishmaniasis. In preparation.

PRESTON, P.M.;CARTER, R. L.; LEUCHARS, E.; DAVIES, A. J. \& DUMONDE, D.C., 1972. Experimental cutaneous leishmaniasis. III. Effects of thymectomy on the course of infections of CBA mice with Leishmania tropica. Clin. Exp. Immunol., 10:337-357.

PRESTON, P.M.; BEHBANANI, K. \& DUMONDE, D.C., 1978. Experimental cutaneous leishmaniasis. VI. Anergy or allergy in the cellular immune response during non-healing infection in different strains of mice. J. Clin. Lab. Immunol., I :207-219.

RADWANSKI, Z.K.; BR YCESON, A.D.M.; PRESTON, P.M. \& DUMONDE, D.C., 1974. Immunofluorescence studies of Leishmania enrietti infection in the guinea pig. Trans. Roy. trop. Med. \& Hig., $68: 124-132$.

SCORZA, J.V., 1981. Observaciones inéditas.

SCORZA, J.V., \& CARNEVALI, M., 1981. Evidences for allocating Monocystis chagasi Adler \& Mayrink, 1961 into the genus $A$ scocystis grassé. 1953 (Gregarinia: Lecudinidae). En prensa.

SCORZA.J.V. \& SCORZA JR., J.V., 1981. En preparación.

SHAW, J.J. \& LAINSON, R., 1972. Leishmaniasis in Brazil. VI. Observations on the seasonal variations of Lutzomyia flaviscutellata in different types of forest and its relationship to enzootic rodent leishmaniasis (Leishmania mexicana amazonensis). Trans. Roy. Soc. trop. Med. \& Hyg., 66 :709-717.

SHERLOCK, I.A. \& SHERLOCK. V.A., 1959. Criaçāo e biologia, em laboratório do "Phlebotomus longipalpis" Lutz \& Neiva, 1912 (Diptera, Psychodidae) Rev. Bras. Biol., 19 :229-250.

SORIANO, P.J., 1977. Caracterización y variaciones estacionales en comunidades de pequeños mamtferos en los llanos occidentales de Venezuela. Tesis de la Facultad de Ciencias, U.L.A., Mérida, Venezuela.

TAUB, J., 1956. The effect of normal human serum on Leishmania. Bull. Res. Counc. of Israel., $6 E$ $: 55+57$.

TORREALBA, J.W.; GOMEZ-NUN̄EZ, J.C. \& ULLOA, G.A., 1972. Isolation of Leishmania braziliensis by intraperitoneal inoculation of blood from a reservoir host into hamsters. Trans. Roy. Soc. trop. Med. \& Hyg. $66: 361$.

URLICH, M.; ORTIZ, D.T. \& CONVIT, J., 1968. The effect of fresh serum on leptomonads of Leish mania. I. Preliminary report. Trans. Roy. Soc. trop. Med. \& Hyg., 62 :825-830.

WARD, R.D., 1977. The colonization of Lutzomyia flaviscutellata (Diptera: Psychodidae), a vector of Leishmania mexicana amazonensis in Brazil. J. Med. Entom., 14 :469-476.

ZUCKERMAN, A., 1975. Current status of the immunology of blood and tissue protozoa. I. Leishmania. Exp. Parasitol., $38: 370-400$.

ZUCKERMAN, A. \& LAINSON, R., 1977. Leishmania. En: "Protozoa of veterinary and medical interest" (Ed. J.P. Kreier). Acad. Press, N.Y. London. 